\title{
Chapter 4 \\ Large Scale Crop Suitability Assessment Under Future Climate Using the Ecocrop Model: The Case of Six Provinces in Angola's Planalto Region
}

\author{
Roland Hunter and Olivier Crespo
}

\subsection{Introduction}

The planalto midlands is a plateau that extends across central Angola, including the majority of the provinces of Huíla, Benguela, Cuanza Sul, Bié, Huambo and Malanje (see Fig. 4.1). The plateau ranges in altitude from 800 to $1600 \mathrm{~m}$ above sea level and extends eastwards from the escarpment above the semiarid coastal region towards the central highlands of the country. The Köppen-Geiger classification defines the climate of the interior plateau as "temperate with dry winters and warm/hot summers" (Köppen-Geiger abbreviations Cwa and Cwb, respectively), while the lowlands between the coast and plateau are classified as arid steppe (BSh). Collectively, the region represented by the arid lowlands of Huíla, Benguela, Cuanza Sul and the comparatively temperate highlands above supports a diverse and productive agriculture sector and is a major producer of economically important staple and cash crops.

There is a risk that climate change will undermine the potential contributions of these crops toward national objectives for sustainable development and food security. However, stakeholders are unable to plan for or respond to the risks posed by climate change to agricultural productivity, food security and socioeconomic development, due to the absence of more detailed information to assess the scope and scale of climate-change impacts.

This study assessed the likely impact of climate change on the future suitability of Angola's planalto region on two staple crops commonly grown in the region,

\footnotetext{
R. Hunter $(\bowtie)$

African Climate and Development Initiative, University of Cape Town,

Cape Town, South Africa

e-mail: roland.hunter@uct.ac.za

O. Crespo

Climate System Analysis Group, University of Cape Town, Cape Town, South Africa

e-mail: olivier@csag.uct.ac.za
} 


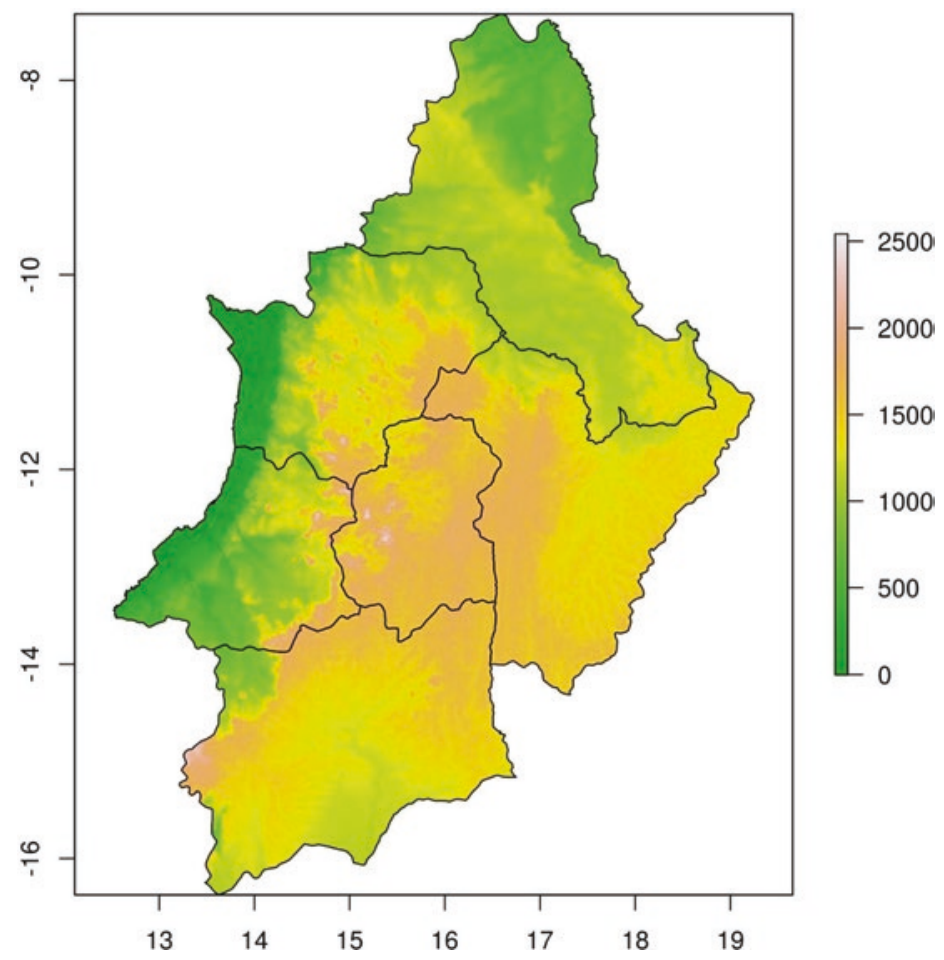

Fig. 4.1 Elevation map of the study region

namely cassava (Manihot esculentum) and maize (Zea mays), which are respectively the first and second most important staple crops by area of cultivation and total production. Using a model-based approach, this study assessed the impacts of climate change on the spatial extent of areas classified as climatically suitable for maize and cassava, between the "historical baseline" period (i.e., the present) and a future date (2050). The goal of these analyses is to improve decision-making and spatial planning regarding which crops, cultivars and farming practices should be promoted as part of a strategy for climate-resilient agricultural and socio-economic development in the planalto.

\subsection{Materials and Methods}

\subsubsection{Sources of Climate Data}

Baseline climate data for the study area was derived from Worldclim historical data, which provides average monthly climate data for minimum, mean and maximum temperature and for precipitation for the period 1960-1990 at a spatial resolution of 
about $1 \mathrm{~km}^{2}$ (a resolution grid of 30 arc-sec) (Hijmans et al. 2005). Interpolations of observed data for the period 1960-1990 are henceforth referred to as the "historical baseline" period.

The future effects of climate change in the study area were computed based on analysis of 29 general circulation models (GCMs) downloaded from the AgMERRA dataset (Ruane et al. 2015). Future climate changes in 2050 for monthly mean temperature (Tmean), monthly minimum temperature (Tmin), and monthly mean precipitation (Precip) were computed assuming the scenario of RCP 8.5 (high emission pathway).

\subsubsection{Analysis of Crop Suitability}

The influence of future climate change predictions on crop suitability was assessed using the Ecocrop suitability model developed by the Food and Agriculture Organisation (Ecocrop 2010), based on the methodologies described in RamirezVillegas et al. (2013). The Ecocrop model calculates the relative suitability of a crop in response to a range of climate variables such as temperature, rainfall; and growing period, thereby generating a suitability index score ranging from 0 (totally unsuitable) to 1 (optimal/excellent suitability) as an output. It should be noted that this study did not undertake any additional ground-truthing or calibration of the range of climate parameters preferred for either crop, and therefore the default EcoCrop parameters were assumed. Suitability index scores were calculated for the range of climate variables reported for the historical baseline period (WorldClim data) and future (GCM predictions for 2050).

\subsection{Results and Discussion}

\subsubsection{Projected Climate Changes}

By 2050 a clear trend of warming is projected across the entire study region throughout all months of the year, with predictions of increases of Tmin and Tmean of approximately $1-2.5^{\circ} \mathrm{C}$. The mean and minimum monthly temperature (Tmean and Tmin) is predicted to increase by $1.5-2{ }^{\circ} \mathrm{C}$ in the eastern and southern interior of the country (including large areas of Bié, Huambo, Huíla and Malanje provinces), and increases of about $1{ }^{\circ} \mathrm{C}$ predicted for the coastal, central and northern regions of the country. Figure 4.2 depicts the spatial distribution of Tmin and Tmean (left and centre, respectively), with anomalies between the two time periods indicated by red shading (bottom row).

With respect to predicted effects of climate change on rainfall, it is projected that the onset of the rainy season (typically September-October) in 2050 will be charac- 


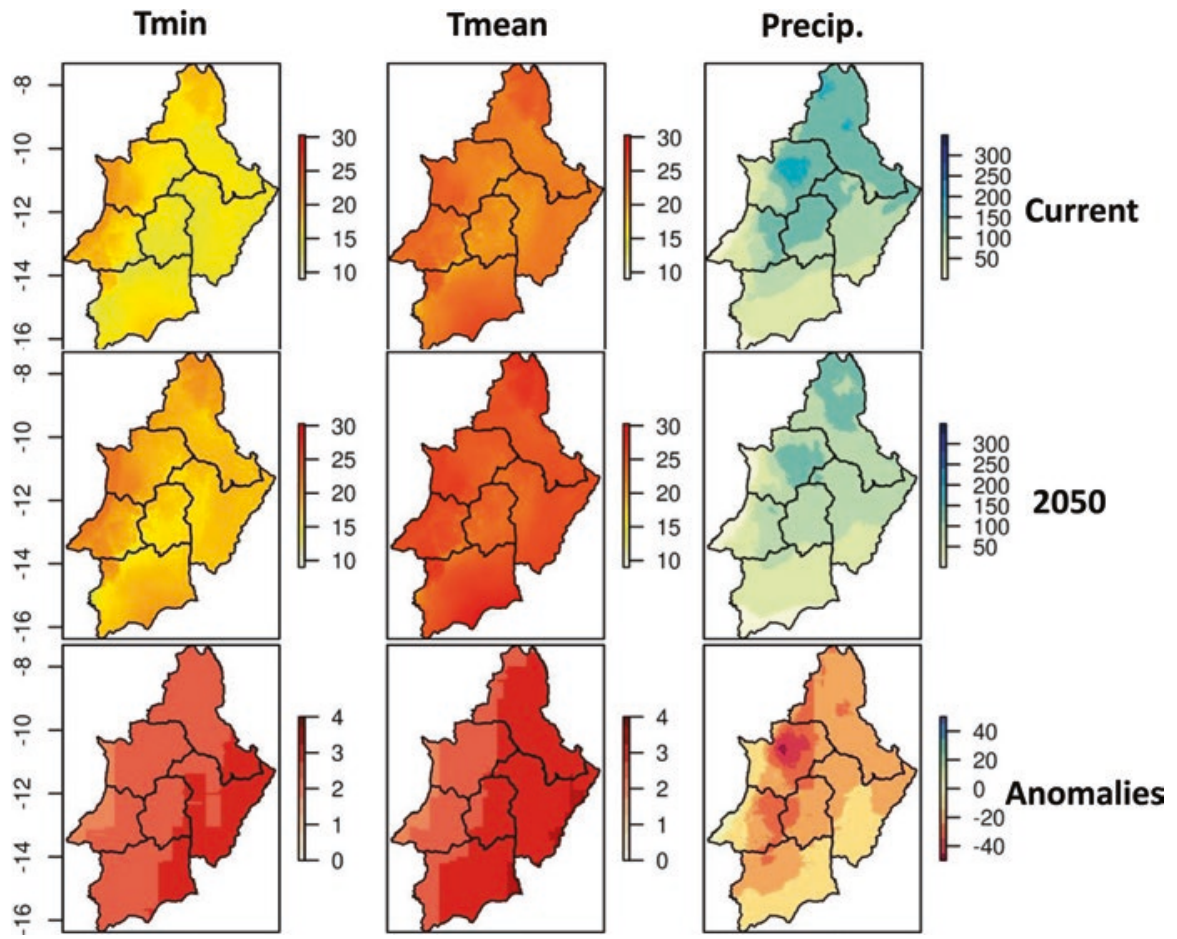

Fig. 4.2 Predicted effects of climate change in study region on average monthly minimum temperature (Tmin) (left), average monthly mean temperature (Tmean) (centre), and mean monthly precipitation (Precip) (right) by the year 2050 for the month of October. Top row depicts baseline (current) climate, centre row depicts predicted future (2050) climate and bottom row indicates anomalies between the two time periods

terised by reduced mean monthly precipitation across the entire region compared to the baseline. Anomalies in monthly rainfall (indicated by red shading in the centre of Fig. 4.2, bottom right) are particularly acute in the northern, central and western extents of the study area at the onset of the rainy season. The trend of reduced rainfall at the onset of the rainy season is projected to continue for the month of November in the central and southern extent of the study area (including the entire extent of Huíla province and majority of Bié and Huambo), whereas the majority of Cuanza Sul and Malanje provinces are projected to benefit from increased rainfall in November by 2050. The majority of the study area is projected to benefit from increased rainfall by 2050 during the midsummer months from December to February, with the exception of the southernmost extent of Huíla province. In March and April, the last months of the traditional maize-growing season, rainfall across the study area is projected to follow two distinct trends: (i) reduced rainfall in the southern and eastern areas, particularly Huíla, Bié and the south-eastern extent of Huambo; and (ii) increased rainfall in the central, western and northern areas, particularly Malanje, northern Huambo, and the highland interior of Cuanza Sul and Benguela provinces. No major changes to rainfall are projected for the dry winter months of May to August. 
The predicted spatial and temporal shifts in temperature and precipitation are likely to result in diverse effects on crop productivity between different crops and regions. Increased temperatures are expected to increase crop water demand, which may lead to increased crop stress or reduced productivity. In certain areas, however, the increased temperatures may increase productivity and extend the length of growing season for some crops, particularly where supplementary irrigation is available or the duration or volume of rainfall received increases (such as in the centre and north of the study region). Climate change is projected to impact the distribution, timing and volume of rainfall, most notably showing a delayed onset of rainfall season or reducing the mean precipitation received during the growing season.

These projected climate changes are likely to result in long-term changes to the timing of various agricultural activities such as field preparation and sowing of seed. In the southern and eastern parts of the study area, notably Huíla and south-east Bié, climate change is expected to reduce precipitation across all months of the growing season, which will reduce the productivity of traditional agricultural approaches and force farmers to adopt new practices and crops. Drought-sensitive crops are likely to be increasingly unreliable or unproductive in the latter areas. In contrast, the central and northern extent of the study region is expected to benefit from increased rainfall during the middle and late summer months, which may extend the growing season or improve the yield potential of certain crops.

\subsubsection{Effects of Climate Change on Distribution of Crop Suitability}

Changes in the total spatial extent of suitable area were calculated for both crops for the period from the present to 2050. Figure 4.3 provides an example of the approach used to depict spatial distribution of crop suitability, where the relative proportion of each colour-shaded area indicates the spatial extent of each corresponding category of crop suitability. Modelled distribution of suitability for cassava and maize is depicted in Figs. 4.4 and 4.5, respectively, where current distribution of crop suitability is depicted on the left, projected future distribution of suitability is depicted on the right, and the anomalies (i.e. changes) between the two periods are depicted in the centre.

\subsubsection{Cassava}

Cassava is an important contributor to the diet and livelihoods of Angola's rural farmers and urban consumers, and is a particularly efficient crop in terms of calories generated per input cost. In addition, cassava is considered to be relatively tolerant of low rainfall conditions, and is increasingly promoted as a climate-resilient crop 


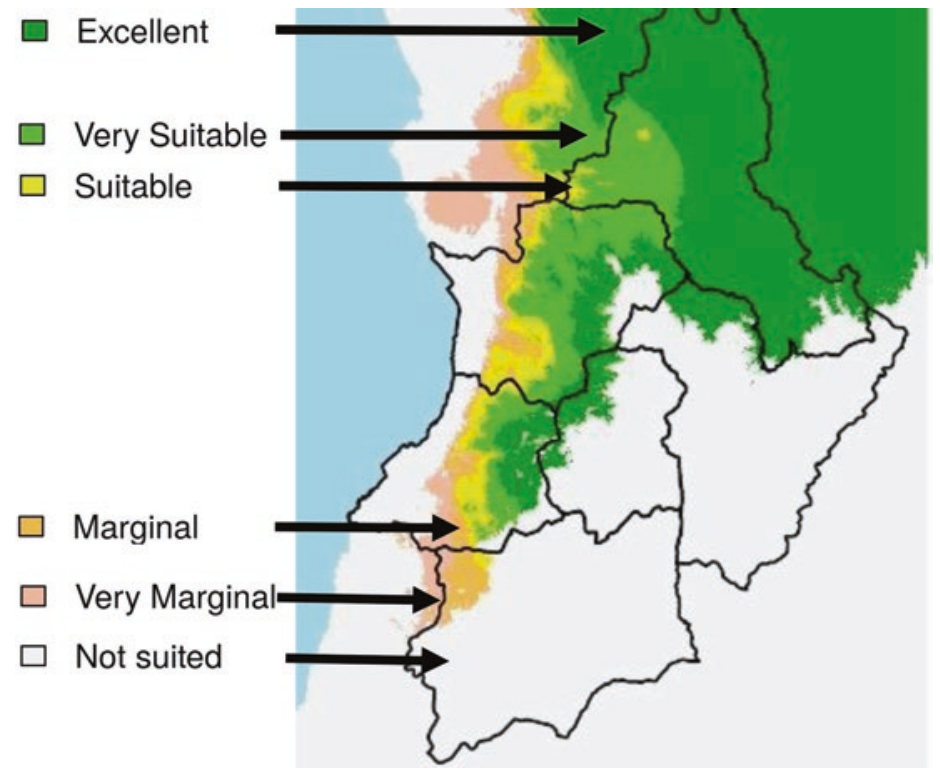

Fig. 4.3 Example demonstration of spatial variability in crop suitability index scores, where the relative proportion of each colour-shaded area indicates the spatial extent of each corresponding category of crop suitability
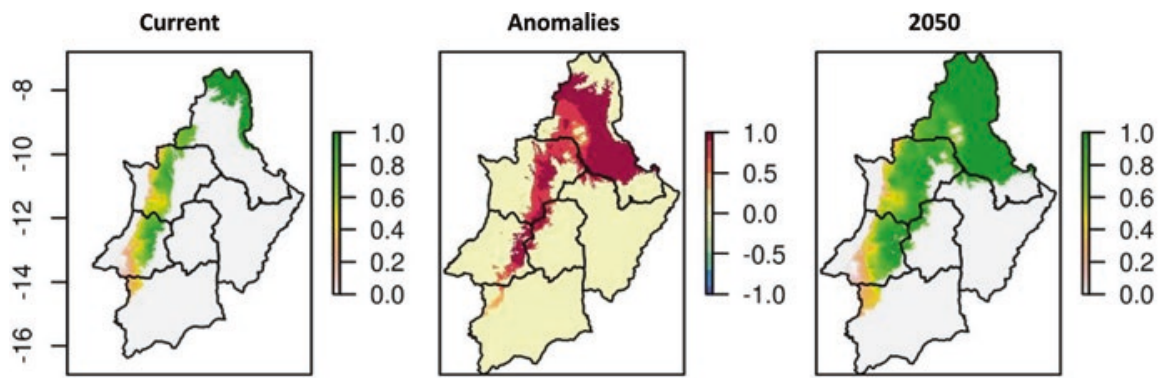

Fig. 4.4 Changes to spatial distribution of areas suitable for production of cassava (Manihot esculentum) in the 'historical' (left) and 'mid-century 2050' (right) scenarios as a result of climate change. Changes between the two-time periods are depicted in the centre
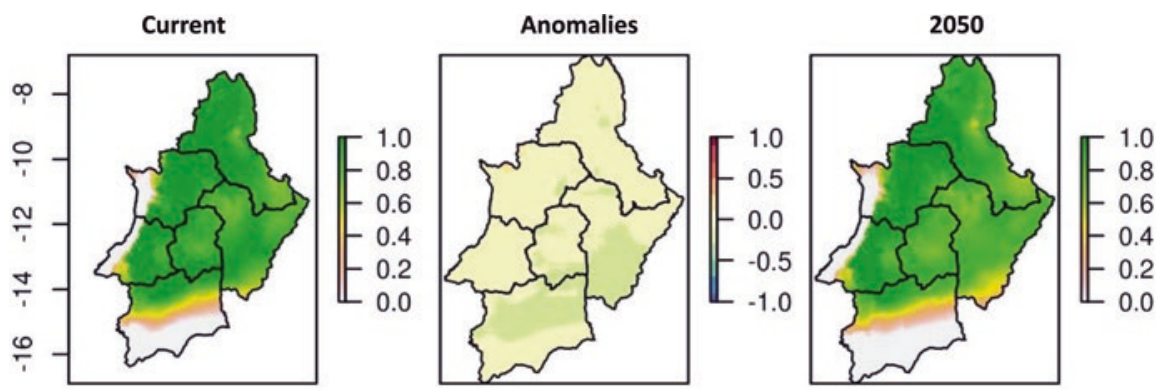

Fig. 4.5 Changes to spatial distribution of areas suitable for production of maize (Zea mays) in the 'historical' (left) and 'mid-century 2050' (right) scenarios as a result of climate change. Changes between the two-time periods are depicted in the centre 
which has the potential to contribute meaningfully to pro-poor economic development (Theodory et al. 2014).

Previous studies of climate-change effects on cassava have suggested that productivity of cassava will not be negatively impacted by climate change and may enjoy slight increases in certain areas of Africa, particularly in Angola (Liu et al. 2008). Jarvis et al. (2010) also reported that climate change will result in a net increase in the range of suitable areas for cassava production (although noting that, despite a net increase in suitable area, other areas are predicted to decline in suitability as a result of temperature increases). The results of this study support the findings of the latter studies, suggesting that the main effect of climate change on cassava production will be to increase the spatial extent and relatively suitability (i.e., localised suitability index score) of existing cassava production zones. EcoCrop analyses predict that the extent of areas suitable for cassava production will increase in the interior highlands above the coastal escarpment, stretching northward from the border of Huambo and Benguela, through Cuanza Sul and northwards into Malanje. This expected improvement in the region's suitability for cassava may be attributable to the projected increase in Tmean from 20 to $21.5^{\circ} \mathrm{C}$, where the optimum temperature range for cassava is $20-29^{\circ} \mathrm{C}$. The trend towards increased suitability for cassava in the latter areas is projected to remain consistent from October through the rest of the summer months.

The suitable range for cassava production is limited by the arid low-lying southern interior of Huíla and western lowlands of coastal Benguela and Cuanza Sul, which are considered to be poorly suited for cassava production in both the baseline and future scenarios. Potential opportunities and adaptation options for such arid regions may include: (i) promotion of sweet potato as a perennial starch-rich alternative to cassava; (ii) adoption of relatively drought-tolerant cereals such as sorghum and millet; and (iii) promotion of increased crop diversification, including combinations of sweet potato, cassava, legumes and drought-tolerant cereals.

It should be emphasised that the potential benefits of cassava as a climateresilient subsistence crop are unlikely to be realised without addressing existing structural barriers in the cassava value chain. Market accessibility for cassava farmers in remote areas is hindered by the short shelf life of unprocessed cassava. Therefore, it is recommended that efforts to promote the cultivation of cassava should be supported by simultaneous investments in capacity-building for improved post-harvest storage, processing and value-adding.

\subsubsection{Maize}

Maize is an important staple crop across Southern Africa and is broadly considered to be prone to climate risk such as drought, irregular rainfall and heat stress. Increased temperatures and an increased frequency of severe drought events pose major concerns to cereal production in sub-Saharan Africa, as do expected increased incidence of diseases, pests and parasitic plants (ADB 2015). Past studies have suggested that projected temperature increases could reduce the productivity of major 
cereal crops, including maize, by $20-30 \%$ by 2050 (Liu et al. 2008; Schlenker and Lobell 2010).

In agreement with past studies, EcoCrop analyses predict that climate change will result in minor but widespread decreases in the crop suitability index score for maize in the planalto region by 2050, particularly at the onset of the rainy season in October. In Huíla province, the absolute spatial extent of areas which are suitable for maize production are predicted to decrease considerably as a result of climate change, to the extent that the entire province is likely to become poorly suited to the crop by 2050. Of the remaining five provinces, the maize-suitable production areas are predicted to remain unchanged in absolute spatial extent but will undergo decreases in crop suitability index score.

In addition to the effects of increasing temperature, a major challenge that will affect maize farmers in Angola is the projected delay in onset of the rainy season as a result of climate change. The trend towards reduced suitability for maize production is likely to be attributable to the predicted decreases in rainfall over the growing season; EcoCrop's parameters specify a minimum seasonal rainfall of $400 \mathrm{~mm}$ and optimum rainfall of at least $600 \mathrm{~mm}$. Analysis of GCMs suggest that onset of rainfall is likely to shift from October/November to December/January by 2050. For households practicing rain-fed maize cultivation, the delayed rains will increase the duration of the "lean" season, when households are reliant on the previous season's harvest. Households therefore will need to adopt new strategies to ensure that food reserves (and adequate seed for planting) can last through this longer lean season. It is unclear whether a long-term shift in the onset of Angola's rainy season will result in a delay to the planting season, or whether changing rainfall patterns will shorten the effective growing season. It is recommended that Angola urgently promote the development and adoption of locally adapted, improved maize cultivars that are more tolerant to heat and drought stress and that can grow to maturity within the confines of a shortened or variable growing season, as well as the promotion of comparatively drought-resilient cereals such as millet and sorghum.

\subsection{Implications for Development}

The approach and results presented in this chapter demonstrate the use of downscaled climate projections and crop suitability models as a useful but broad-level means of assessing the possible effects of climate change on the temporal and spatial distribution of crop suitability. This is particularly important in countries such as Angola where agronomic data and climate measurements are not readily available. In this case study of six provinces in the planalto region of Angola, the diverse impacts of climate change on the crops analysed cannot be easily generalised across the entire study area and indicate the need for detailed local-level studies and strategies for intervention. 
The semi-arid regions in the south of Huíla and in the western lowlands of Benguela and Cuanza Sul have climates that are at the limit of the suitable range of the crops analysed. As a result, the spatial range of suitability for heat- and droughtsensitive crops such as maize is projected to be reduced in the low-lying, coastal and southerly parts of the study area by 2050 . Climate change will also reduce the duration-or delay the onset-of the growing season for rain-fed crops such as maize across most of the study region. The negative effects of climate change on staple crops such as maize has the potential to undermine the wellbeing of rural households and jeopardise long-term objectives for economic development in climatevulnerable regions such as Angola. In the affected regions, the primary options for adaptation include the promotion of both climate-resilient cultivars of maize and of alternative crops such as cassava, millet or sorghum.

However, despite the apparent threats posed by the declining productivity of certain crops in response to climate change, this study also indicates that climate change may create new opportunities for agricultural development through promotion of climate-resilient staples and alternative crops. In addition to crop-specific considerations, adaptation options for Angola's agriculture sector may include promotion of rural finance, food processing, development of irrigation infrastructure, increased access to extension services, development of early-warning systems and development of rural transport infrastructure.

These analyses provide a demonstration of the applications of crop suitability models for the identification of potential climate vulnerabilities related to food security, as well as identification of potential climate-resilient subsistence crops to be promoted as a strategy to adapt to changing climate conditions. Modelled approaches such as those applied in this study can be further strengthened through the inclusion of measures for calibration and incorporating field-level measurements and local crop performance data.

\section{References}

ADB (African Development Bank) (2015) Cereal crops: rice, maize, millet, sorghum, wheat. United Nations: Economic Commission for Africa

Ecocrop (2010) Ecocrop database. Food and Agriculture Organization of the United Nations, Rome http://ecocrop.fao.org/

Hijmans RJ, Cameron SE, Parra JL et al (2005) Very high resolution interpolated climate surfaces for global land areas. Int J Climatol 25:1965-1978 http://www.worldclim.org/version1

Jarvis A, Ramirez J, Anderson B et al (2010) Scenarios of climate change within the context of agriculture. In: Reynolds MP (ed) Climate change and crop production. CAB International, Wallingford, pp 9-37

Liu J, Fritz S, Wesenbeeck CFA et al (2008) A spatially explicit assessment of current and future hotspots of hunger in Sub-Saharan Africa in the context of global change. Glob Planet Chang 64:225-235 
Ramirez-Villegas J, Jarvis A, Laderach P (2013) Empirical approaches for assessing impacts of climate change on agriculture: the EcoCrop model and a case study with grain sorghum. Agric For Meteorol 170(15):67-78

Ruane AC, Goldberg R, Chryssanthacopoulos J (2015) AgMIP climate forcing datasets for agricultural modeling: merged products for gap-filling and historical climate series estimation. Agric For Meteorol 200:233-248 https://data.giss.nasa.gov/impacts/agmipcf/agmerra/

Schlenker W, Lobell DB (2010) Robust negative impacts of climate change on African agriculture. Environ Res Lett 5:014010

Theodory M, Honi B, Sewando P (2014) Consumer preference for cassava products versus different technologies. Int J Innov Sci Res 2(1):143-151

Open Access This chapter is licensed under the terms of the Creative Commons Attribution 4.0 International License (http://creativecommons.org/licenses/by/4.0/), which permits use, sharing, adaptation, distribution and reproduction in any medium or format, as long as you give appropriate credit to the original author(s) and the source, provide a link to the Creative Commons license and indicate if changes were made.

The images or other third party material in this chapter are included in the chapter's Creative Commons license, unless indicated otherwise in a credit line to the material. If material is not included in the chapter's Creative Commons license and your intended use is not permitted by statutory regulation or exceeds the permitted use, you will need to obtain permission directly from the copyright holder.

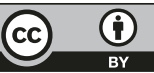

